\title{
Tracheobronchial adenoid cystic carcinoma treated with radical radiochemotherapy: Case report and review of literature
}

\author{
Chira Ranjan Khadanga ${ }^{1}$, Gangadhar Vajrala ${ }^{2, *}$, I Satish Rao ${ }^{3}$ and Rajeev Ratan Jain ${ }^{4}$
}

\author{
${ }^{1}$ Department of Radiation Oncology, Hemalata Hospital \& Research Centre, Bhubaneswar, Odisha-751023, India \\ ${ }^{2}$ Department of Radiation Oncology, Krishna Institute of Medical Sciences, Minister Road, Secunderabad-500003, Telangana, India \\ ${ }^{3}$ Department of Pathology, Krishna Institute of Medical Sciences, Minister Road, Secunderabad-500003, Telangana, India \\ ${ }^{4}$ Department of Radiotherapy, Regional Cancer Centre, PTJNM Medical College, Raipur, Chhattisgarh-492001, India
}

\begin{abstract}
Adenoid cystic carcinoma (ACC) is a low-grade malignancy of the elderly but has shown aggressive behavior. It is most commonly found in minor salivary glands and rarely in lacrimal glands, tracheobronchial tree, lung parenchyma, breast, cervix, skin, esophagus, prostate. The standard of care of ACC is essentially surgery followed by post-operative adjuvant radiation therapy depending upon various adverse features. Here we report an unusual tracheo-bronchial ACC in a 32-year-old lady who was treated with radical radiotherapy under image guidance along with concurrent chemotherapy using intravenous cisplatin on weekly basis. Response evaluation with ${ }^{18}$ FDG PET-CECT three months after the completion of treatment showed complete response, and has also remained disease free clinically at 3 years follow-up, without any late radiation toxicity.
\end{abstract}

Keywords: adenoid cystic carcinoma; radiation therapy; ${ }^{18}$ FDG PET-CECT

*Corresponding author: Dr. Gangadhar, MBBS, MDRT, MPH, CLRA, Radiation Oncologist, Department of Radiation Oncology, Krishna Institute of Medical Sciences, Minister Road, Secunderabad-500003, Telangana, India. Email: gvajrala@gmail. com

Received 22 June 2017; Revised 31 August 2017; Accepted 15 September 2017; Published 25 September 2017

Citation: Khadanga CR, Vajrala G, Satishrao I, Jain RR. Tracheobronchial adenoid cystic carcinoma treated with radical radiochemotherapy: Case report and review of literature. J Med Sci Res. 2017; 5(4):142-145. DOI: http://dx.doi.org/10.17727/ JMSR.2017/5-27

Copyright: (C) 2017 Khadanga CR, et al. Published by KIMS Foundation and Research Center. This is an open-access article distributed under the terms of the Creative Commons Attribution License, which permits unrestricted use, distribution, and reproduction in any medium, provided the original author and source are credited.

\section{Introduction}

Adenoid cystic carcinoma (ACC) is a rare tumor which is although indolent but has shown persistent and recurrent growth, metastasis and death [1]. It is commonly encountered in the minor salivary glands, constituting approximately $10 \%$ of all the head-neck cancers [2] along with occasional incidences in other uncommon sites like the upper respiratory tract, lacrimal glands, tracheobronchial tree, lung parenchyma, breast, cervix, skin, esophagus, prostate [3]. In this background, primary lung ACC is extremely rare and accounts for approximately $0.04 \%-0.2 \%$ of all lung cancers [4]. Histopathogically, it is a low-grade malignancy having biphasic components (e.g. epithelial and myoepithelial cells) showing three distinct types of 
growth patterns e.g. tubular, cribriform and solid [5]. It occurs most frequently in the fourth to sixth decades of life without any sex predominance [6]. It is very rarely seen below 30 years. Its etiology largely remains unknown. As of now, standard guidelines for the optimal management ACC are still evolving with complete surgical excision has been accepted as the most effective treatment. There is a growing evidence towards the encouraging role of post-operative adjuvant radiation therapy (RT), which has shown an improved survival compared with surgery alone in head-neck ACC $[7,8]$. Various clinico-pathological factors have also been identified with an unfavorable effect on survival in head-neck ACC like old age, tumor location, advanced stage, solid histological subtype, high grade, major nerve involvement and the presence of perineural invasion or a positive surgical margin $[9,10]$.

The present case report describes an unusual inoperable tracheo-bronchial ACC which presented with complete opacity of one lung and wasinoperable due to its critical location at the bifurcation of the bronchus. She was treated conservatively with image guided radiation therapy (IGRT) and followed up to 3 years with no late radiation toxicity.

\section{Case report}

A 32-year-old woman presented with chief complaints of progressive shortness of breath and occasional mild haemoptysis of one month duration. There was no history of cough, chest pain or fever. Her past medical history was unremarkable. General physical examination was essentially normal. Respiratory system examination revealed dull percussion note and absence of breath sounds in left lung. Other systemic examination findings were essentially normal. The hematological and biochemical parameters were also within normal limits.

X-ray chest revealed complete opacity of the left lung with ipsilateral mediastinal shifting. Fibreoptic broncoscopy showed glistening pinkish growth with near complete obstruction of the left main bronchus. Functional imaging with ${ }^{18}$ Fluro-deoxy glucose positron emission tomography-contrast enhancing computed tomography $\left({ }^{18}\right.$ FDG PETCECT) showed a mass of size $6.7 \mathrm{~cm} \times 3 \mathrm{~cm} \times 5 \mathrm{~cm}$ encasing and occluding the trachea and left main bronchus causing distal collapse of left lung (Figure
1). The histopathology was reported as ACC of the bronchus (Figure 2). Complete surgical excision was not possible in view of critical anatomical location and hence she was advised for intent radical radiotherapy with concurrent chemotherapy. She was planned for radiation therapy using image guided-intensity modulated radiation therapy (IGIMRT). Daily patient set-up and treatment portal verification was done using on-board electronic portal imaging device (EPID) as well as cone-beam computed tomography (CBCT) before treatment delivery. Concurrent chemotherapy was also given on weekly basis using intravenous cisplatin $30 \mathrm{mg} /$ $\mathrm{m}^{2}$ body surface area after ensuring adequate creatinine clearance parameter along with contemporary anti-emesis premedications as well as adequate intravenous hydration. She received a total dose of 60Gy in 30 daily fractions over 45 days. She completed treatment uneventfully without any interruptions. On follow-up after 3 months, ${ }^{18}$ FDG PET-CECT revealed complete metabolic response. The patient has now completed 3 years of follow up with no evidence of disease as well.

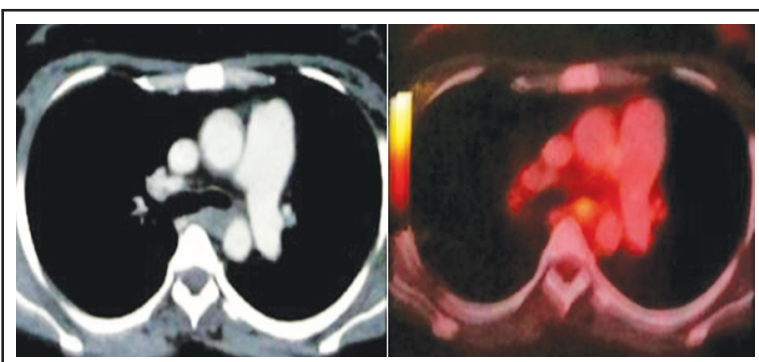

Figure 1: Diagnostic PETCT showing metabolically active mass near the carina.

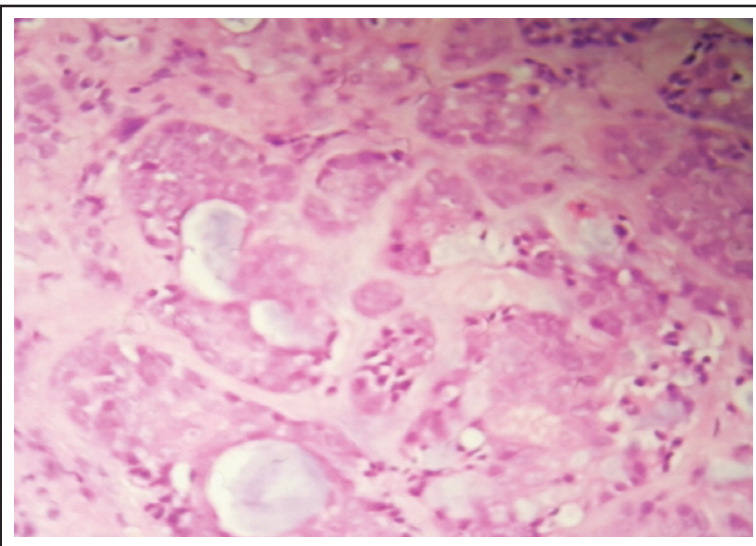

Figure 2: Biopsy showing adenoid cystic carcinoma.

\section{Discussions}

Although ACC is a variant of adenocarcinoma, it has a distinct histolopathological feature and clinico- 
biological behavior. Primary lung ACC generally arises from the tracheobronchial glands present in the airway sub mucosa, with a morphology similar to salivary gland ACC. There is a paucity of information in various literatures regarding the primary lung ACC, its clinico-biological behavior, optimum management as well as patterns of failure. A correlation between the clinical behavior of ACC and their histological patterns has been attempted with the solid histological pattern showing a more aggressive clinical course and early distant metastases, in contrast to the cribriform type which in contrast shows a more benign behavior [11]. Till now, complete surgical resection appears to be the most accepted and effective treatment. In a retrospective study by Conlan et al. from Mayo clinic, showed superior treatment results in patients with complete surgical resection [11]. Similarly, in a literature review by Yokuchi et al. [12] the long term outcomes were favorable in patients who underwent surgical resection. Some studies also described the use of adjuvant radiation therapy (RT) and chemotherapy. However, the exact role of RT is doubtful so far as the radiation sensitivity is concerned. Some studies have been described it as radiosensitive [13] while few has reported it as radioresistant. These are also generally not sensitive to chemotherapy but may show partial response to targeted novel therapies. Recently KIT expression by immune-histochemistry (IHC) has been detected ACC of head-neck as well as lung. Aubry et al. [14] analysed the primary salivary gland type tumors of the lung diagnosed between 1972 and 2002 and found almost $67 \%$ patients (33 out of 49 ) showed KIT expression positivity by IHC. Imatinib mesylate, a novel targeted agent for the c-KIT overexpression linked tyrosine kinase inhibition has also shown a promising result. In a phase-II multicentric study by Hotte et al. [15], imatinib has shown an encouraging result. In this study, metastatic or recurrent lung ACC, which were overexpressing c-KIT (by CD117) given imatinib with a response assessment after 3 months. Out of a total 6 patients enrolled in, 3 patients achieved a non-progressive and stable disease (50\%) and one patient achieved a partial response, which implicates a definitive benefit of imatinib mesylate in accelerated tumor growth and c-KIT overexpression.

We here observed a good and durable response to intent radical radiation therapy without any treatment related toxicity. Our experience is in favor of a radiosensitive nature of the tumor as observed by Grillo et al. [13]. We also observed a satisfactory tumoricidal RT dose at 60Gy/30fractions/ 7 weeks with excellent patient compliance as well as acceptable minimum treatment related toxicity.

\section{Conclusion}

Given the rarity of tracheo-bronchial adenoid cystic carcinoma (ACC), standard treatment recommendation are lacking with maximum surgical resection is the current accepted practice as of now. We have observed a satisfactory as well as complication free long-term durable response to radical dose IG-IMRT in an young female with inoperable primary tracheo-bronchial ACC.

\section{Conflicts of interest}

Authors declare no conflicts of interest.

\section{Referrences}

[1] Seaver PR Jr, Kuehn PG. Adenoid cystic carcinoma of the salivary glands. A study of ninety-three cases. Am J Surg. 1979; 137(4):449-455.

[2] Spiro RH, Huvos AG, Strong EW. Adenoid cystic carcinoma of salivary origin. A clinicopathologic study of 242 cases. Am J Surg. 1974; 128(4):512-520.

[3] Waldron CA. Face, lips, tongue, teeth, oral soft tissues, jaws, salivary glands and neck. In: kissane JM, ed. Anderson's Pathology; ST. Louis: CV Mosbay. 1990; 1138-1139.

[4] Kim JH, Ahn SH, Kim JM, Lee SY. Metachronous adenoid cystic carcinoma in the peripheral lung and at base of the tongue. Clin Exp Otorhinolaryngol. 2014; 7(3):232-235.

[5] Matsuba HM, Spector GJ, Thawley SE, Simpson JR, Mauney $\mathrm{M}$, et al. Adenoid cystic salivary gland carcinoma. A histopathologic review of treatment failure patterns. Cancer 1986; 57(3):519-524.

[6] Moran CA, Suster S, Koss MN. Primary adenoid cystic carcinoma of the lung. Cancer 1994; 73(5):1390-1397.

[7] Le QT, Birdwell S, Terris DJ, Gabalski EC, Varghese A, et al. Postoperative irradiation of minor salivary gland malignancies of the head and neck. Radiother Oncol. 1999; 52(2):165-171.

[8] Chen AM, Bucci MK, Weinberg V, Garcia J, Quivey JM, et al. Adenoid cystic carcinoma of the head and neck treated by surgery with or without postoperative radiation therapy: prognostic features of recurrence. Int J Radiat Oncol Biol Phys. 2006; 66(1):152-159.

[9] Khan AJ, DiGiovanna MP, Ross DA, Sasaki CT, Carter D, et al. Adenoid cystic carcinoma: a retrospective clinical review. Int. J. Cancer. 2001; 96(3):149-158.

[10] Prokopakis EP, Snyderman CH, Hanna EY, Carrau RL, Johnson JT, et al. Risk factors for local recurrence of adenoid cystic carcinoma: the role of postoperative radiation therapy. Am J Otolaryngol. 1999; 20(5):281-286. 
[11] Conlan AA, Payne WS, Woolner LB, Sanderson DR. Adenoid cystic carcinoma(cylindroma) and mucoepidermoid carcinoma of the bronchus. Factors affecting the survival. J Thorac Cardiovasc Surg. 1978; 76(3):369-377.

[12] Yokouchi H, Otsuka Y, Otoguro Y, Takemoto N, Ito K, et al. Primary peripheral adenoid cystic carcinoma of the lung and literature comparison of features. Intern Med. 2007; 46(21):1799-1803.

[13] Grillo HC, Mathisen DJ. Primary tracheal tumors: Treatment and results. Ann Thorac Surg. 1990; 49(1):69-77.

[14] Aubry MC, Heinrich MC, Molina J, Lewis JE, Yang P, et al. Primary adenoid cystic carcinoma of the lung: Absence of KIT mutations. Cancer 2007; 110(11):2507-2510.

[15] Hotte SJ, Winquist EW, Lamont E, MacKenzie M, Vokes E, et al. Imatinib mesylate in patients with adenoid cystic cancers of the salivary glands expressing c-kit: A Princess Margaret Hospital phase II consortium study. J Clin Oncol. 2005; 23(3):585-590. 